\title{
An application of DEMATEL technique to find the effect of different factors influencing outsourcing activities in water and switch organization
}

\author{
Fatimah Hemati $^{\mathrm{a}}$ and Younos Vakil Alroaia ${ }^{\mathbf{b}^{*}}$
}

\begin{abstract}
${ }^{a}$ Master Student, Department of Management, Semnan Branch, Islamic Azad University, Semnan, Iran
${ }^{b}$ Assistant Professor, Department of Management, Semnan Branch, Islamic Azad University , Semnan , Iran

A R T I C L E I N F O

Article history:

Received March 28, 2012

Received in Revised form

July, 19, 2012

Accepted 10 August 2012

Available online

11 August 2012

Keywords:

DEMATEL

Outsourcing

Water resources management

Multiple criteria decision making

A B S T R A C T

Outsourcing plays an important role on reducing unnecessary activities in any organization and helps focus only on value added activities. Water resource organization in each city is responsible to supply fresh and clean water and dispose switch as efficiently as possible and all citizens normally benefit from these organizations. The proposed model of this paper uses DEMATEL to prioritize 14 different factors influencing on outsourcing activities. The survey was performed from October, 2011 to May, 2012 among employees on work for water resource organization in city of Semnan, Iran. The survey chooses a sample of 92 employees out of 120 people who worked for this organization. Cronbach alpha is calculated as $90 \%$, which is well above the minimum acceptable level. The results of the survey indicate that expediting work process is the most important factor while reducing the cost is considered as the least important factors among 14 different items.
\end{abstract}

\section{Introduction}

During the past few decades, there have been increasing competitions among business units and they do their best to increase their efficiencies through reducing unnecessary activities, and focusing more on core value added business structures. Outsourcing is one of the most important activities, which could be performed through business units to reduce unnecessary expenditures (Bardhan \& Kroll, 2008). There are several reasons to believe that organizations attempt to outsource their activities. By justifying that outsourcing decisions are strategic, this strategy can be the source of many fundamental changes in the organization. Therefore, the most important point is to manage these crucial changes, precisely. The other point is that outsourcing does not mean absolve responsibility from an outsourcing organization or buyer. It means to entrust activities to outside organizations or people in order to achieve better efficiency, better responsiveness, and reduction of costs. It does not also mean to entrust the whole responsibilities (Espino-Rodriguez \& Padron-Robaina, 2004). Agrawal et al. (2006) performed another study to investigate market reactions to e-business

* Corresponding author. Tel.: +989122316247

E-mail addresses: younos.vakil@gmail.com (Y. Vakil Alroaia) 
outsourcing announcements. Successful outsourcing is accomplished through proper implementation of strategic planning, execution and control and strategic planning refers to comprehensive and suitable plans within the outsourcing phases (Lau \& Hurly, 1997). Masaaki et al. (2008) explained that outsourcing, performance, and the role of e-commerce maintain a dynamic perspective. A good implementation of outsourcing activities requires a good knowledge on different factors, which means we need to use multi criteria decision making (MCDM).

Bottani and Rizzi (2006), for instance, used Technique for Order Preference by Similarity to Ideal Solution (TOPSIS) for outsourcing activities. TOPSIS, originally developed by Hwang and Yoon in 1981, is a simple but sophisticated ranking methodology used in many real-world applications of science and engineering (Chang et al., 2010). The standard TOPSIS method chooses alternatives, which simultaneously have the shortest distance from the positive ideal solutions and the longest distance from the negative-ideal solutions. The positive ideal solution maximizes the desirable criteria and minimizes the undesirable criteria, whereas the negative ideal solution maximizes the undesirable criteria and minimizes the desirable criteria.

TOPSIS makes full implementation of attribute information, provides a cardinal ranking of alternatives, and does not need attribute preferences to be independent. To apply this technique, attribute values must be numeric, monotonically increasing or decreasing, and have commensurable units (Chen \& Hwang, 1992; Yoon \& Hwang, 1995). Hsu and Hsu (2008), for instance, used TOPSIS with an adatpation of entropy for optimizing the information outsourcing practices of primary care medical organizations. To handle outsourcing decision-making problems, Kahraman et al. (2009) presented a fuzzy group decision-making methodology based on TOPSIS where they used fuzzy TOPSIS approach to specify the ranking of alternatives according to an aggregated decision matrix and weight vector and was based on the individual decision matrices and weight vectors.

Opricovic and Tzeng (2007) used an extended VIKOR method in comparison with outranking methods for an application of outsourcing problem. Amiri et al. (2011) presented a method to prioritize the locations of distribution centers in a supply chain using balanced scorecard to categorize the most important attributes affecting the location of distribution centers and the attributes are ranked based on decision making trial and evaluation laboratory (DEMATEL) method (Fontela \& Gabus, 1976). The implementation of the proposed model of this paper was also applied for a realworld case study of oil company and the results are analyzed under different scenarios. Tseng (2009) in another assignment used a causal and effect decision making model of service quality expectation based on another extension of DEMATEL technique called grey-fuzzy DEMATEL approach. Zhou et al. (2011) determined critical success factors in emergency management using a fuzzy DEMATEL method. Klaas et al. (2001) performed another investigation on the effect of outsourcing human resources on increasing the efficiency of organizations. Lin et al. (2011) used DEMATEL method to explore the core competences and causal effect of the IC design service company for an empirical case study.

Belcourt (2006) performed a comprehensive investigation to detect the advantages and disadvantages of outsourcing activities. Moon (2010) developed a model for partial outsourcing under a market uncertainty to provide a firm with an outsourcing strategy and making a corresponding support decision system. Based on this model, management implications were provided on how outsourcing timing strategy should vary when outsourcing environments such as market uncertainty change. As Moon (2010) reports, when market becomes more stable, higher marginal profits are expected from outsourcing. When a firm outsources more shares and its effort at the preparation stage is more efficient, it can outsource earlier. Furthermore, Moon (2010) conducted a comparative study of a real option approach and a net present value method to conclude that NPV underestimates the firm's values and proposes the earlier partial outsourcing. 
The proposed study of this paper uses DEMATEL technique to prioritize the important factors influencing outsourcing activities in water management organization of the city of Semnan, Iran. The organization of this paper first presents details of our survey characteristics in section 2 and section 3 demonstrates details of our results. Finally, concluding remarks are given in the last to summarize the contribution of the paper.

\section{The proposed DEMATEL technique}

As we have explained earlier, DEMATEL is a method for building a structural model involving causal relationships among complex factors (Gabus \& Fontela, 1972, 1973). DEMATEL was developed by the science and human affairs program of the Battelle Memorial Institute of Geneva over the period of 1972-1976 and it was implemented to solve the complicated and intertwined problem group. The infrastructure, according to the properties of objective affairs, can confirm the interdependence among the variables/attributes and restrict the relationships, which reflect the properties with an essential system and development trend. The procedures of the DEMATEL method (Fontela \& Gabus, 1976) as follows,

Step 1: Generating the direct-relation matrix. We apply four scales for measuring the relationship among various criteria: 0 (no influence), 1 (low influence), 2 (high influence), and 3 (very high influence). Next, decision makers prepare sets of the pair-wise comparisons in terms of effects and direction between criteria. Then the initial data can be obtained as the direct-relation matrix which is a $n \times n$ matrix $A$ where each element of $a_{i j}$ is denoted as the degree in which the criterion $i$ affects the criterion $j$.

Step 2: Normalizing the direct-relation matrix. Normalization is performed using the following,

$X=k . A$

$k=\frac{1}{\max _{1 \leq i \leq n} \sum_{j=1}^{n} a_{i j}} \cdot i, j=1,2, \ldots, n$

Step 3: Attaining the total-relation matrix. Once the normalized direct-relation matrix $X$ is obtained, the total relation matrix $T$ can be acquired by using Eq. (3), where $I$ is denoted as the identity matrix

$T=X(1-X)^{-1}$

Step 4: Producing a causal diagram. The sum of rows and the sum of columns are separately denoted as vector $D$ and vector $R$ through Eqs. (4-6). Then, the horizontal axis vector $(D+R)$ named "Prominence"' is made by adding $D$ to $R$, which reveals the relative importance of each criterion. Similarly, the vertical axis $(D-R)$ named "Relation"' is made by subtracting $D$ from $R$, which may divide criteria into a cause and effect groups. Generally, when $(D-R)$ is positive, the criterion belongs to the cause group and when the $(D-R)$ is negative, the criterion represents the effect group. Therefore, the causal diagram can be obtained by mapping the dataset of the $(D+R, D-R)$, providing some insight for making decisions.

$$
\begin{aligned}
T & =\left[t_{i j}\right]_{n \times n^{\prime}} \quad i, j=1,2, \ldots, n \\
D & =\left[\sum_{j=1}^{n} t_{i j}\right]_{n \times 1}=\left[t_{i}\right]_{n \times 1} \\
R & =\left[\sum_{i=1}^{n} t_{i j}\right]_{1 \times n}=\left[t_{. j}\right]_{1 \times n}
\end{aligned}
$$


where vector $D$ and vector $R$, respectively denote the sum of rows and the sum of columns from totalrelation matrix $T=\left[t_{i j}\right]_{n \times n}$.

Step 5: Obtaining the inner dependence matrix. In this step, the sum of each column in total-relation matrix is equal to 1 by the normalization method, and then the inner dependence matrix can be acquired.

\section{The case study}

The case study of this paper is associated with water and switch organization of the city of Semnan located in province of Semnan, Iran. The study designs a questionnaire and distributes it among different employees of this organization. The sample size is calculated as follows,

$$
n=\frac{N \times z_{\alpha / 2}^{2} \times p \times q}{\varepsilon^{2} \times(N-1)+z_{\alpha / 2}^{2} \times p \times q},
$$

where $N$ is the population size, $p=1-q$ represents the yes/no categories, $z_{\alpha / 2}$ is CDF of normal distribution and finally $\varepsilon$ is the error term. Since we have $p=0.5, z_{\alpha / 2}=1.96$ and $N=120$, the number of sample size is calculated as $n=92$. Table 1 shows all potential factors, which were investigated in our survey. In our survey, 30 people were female and 62 employees were male. In terms of educational background, 23 employees only finished high school, 46 maintained bachelor degrees, 14 people finished their master degree and 9 employees had $\mathrm{PhD}$ degree. In terms of age, 10 people were 25 to 30 years old, 35 people were between 31 and 40, 35 people were in the range of 41-50 and 26 people were older than 51 years. Cronbach alpha was calculated as $90 \%$, which is well above the minimum acceptable level. Table 2 shows the effects of each factors used for DEMATEL implementation.

\section{Table 1}

Important factors influencing outsourcing activities

\begin{tabular}{llll}
\hline Factor & & Factor & \\
\hline $\mathrm{X}_{1}$ & Expediting activities' accomplishment & $\mathrm{X}_{8}$ & More concentration on core activities \\
$\mathrm{X}_{2}$ & Better control on activities & $\mathrm{X}_{9}$ & Cost reduction \\
$\mathrm{X}_{3}$ & Increase in quality of services & $\mathrm{X}_{10}$ & Changing the fixed costs into variable \\
$\mathrm{X}_{4}$ & Using better available skills & $\mathrm{X}_{11}$ & Saving management time \\
$\mathrm{X}_{5}$ & Increasing the sense of competition & $\mathrm{X}_{12}$ & Employee reduction \\
$\mathrm{X}_{6}$ & Reducing the risk & $\mathrm{X}_{13}$ & Releasing the equity \\
$\mathrm{X}_{7}$ & Achieving new ideas & $\mathrm{X}_{14}$ & Achieving better technology \\
\hline
\end{tabular}

\section{Table 2}

The relative effects of all 14 factors

\begin{tabular}{llllllllllllllll}
\hline & $\mathrm{X}_{1}$ & $\mathrm{X}_{2}$ & $\mathrm{X}_{3}$ & $\mathrm{X}_{4}$ & $\mathrm{X}_{5}$ & $\mathrm{X}_{6}$ & $\mathrm{X}_{7}$ & $\mathrm{X}_{8}$ & $\mathrm{X}_{9}$ & $\mathrm{X}_{10}$ & $\mathrm{X}_{11}$ & $\mathrm{X}_{12}$ & $\mathrm{X}_{13}$ & $\mathrm{X}_{14}$ & $\mathrm{Total}$ \\
\hline $\mathrm{X}_{1}$ & 0 & 1 & 3 & 0 & 2 & 1 & 0 & 2 & 4 & 3 & 4 & 3 & 0 & 3 & 26 \\
$\mathrm{X}_{2}$ & 4 & 0 & 4 & 3 & 0 & 4 & 2 & 3 & 4 & 3 & 3 & 1 & 1 & 0 & 32 \\
$\mathrm{X}_{3}$ & 1 & 1 & 0 & 2 & 4 & 3 & 1 & 2 & 3 & 3 & 3 & 1 & 0 & 1 & 25 \\
$\mathrm{X}_{4}$ & 4 & 4 & 4 & 0 & 0 & 3 & 2 & 1 & 3 & 2 & 1 & 2 & 1 & 0 & 27 \\
$\mathrm{X}_{5}$ & 3 & 1 & 3 & 2 & 0 & 1 & 4 & 2 & 1 & 0 & 0 & 0 & 0 & 4 & 21 \\
$\mathrm{X}_{6}$ & 2 & 3 & 3 & 1 & 3 & 0 & 0 & 4 & 3 & 3 & 1 & 1 & 2 & 2 & 28 \\
$\mathrm{X}_{7}$ & 2 & 2 & 4 & 3 & 4 & 4 & 0 & 2 & 3 & 3 & 0 & 0 & 2 & 4 & 33 \\
$\mathrm{X}_{8}$ & 4 & 4 & 4 & 3 & 2 & 3 & 2 & 0 & 3 & 1 & 2 & 1 & 2 & 3 & 34 \\
$\mathrm{X}_{9}$ & 0 & 0 & 2 & 1 & 3 & 4 & 0 & 1 & 0 & 3 & 0 & 0 & 3 & 2 & 19 \\
$\mathrm{X}_{10}$ & 0 & 0 & 1 & 0 & 1 & 3 & 0 & 1 & 2 & 0 & 0 & 0 & 4 & 1 & 12 \\
$\mathrm{X}_{11}$ & 3 & 4 & 1 & 1 & 0 & 2 & 2 & 3 & 1 & 0 & 0 & 1 & 0 & 2 & 20 \\
$\mathrm{X}_{12}$ & 0 & 0 & 0 & 0 & 2 & 0 & 0 & 0 & 4 & 4 & 1 & 0 & 2 & 2 & 15 \\
$\mathrm{X}_{13}$ & 2 & 2 & 3 & 3 & 4 & 4 & 2 & 2 & 3 & 4 & 1 & 1 & 0 & 4 & 35 \\
$\mathrm{X}_{14}$ & 4 & 4 & 4 & 4 & 4 & 4 & 4 & 3 & 3 & 2 & 3 & 4 & 2 & 0 & 45 \\
\hline
\end{tabular}


The implementation of DEMATEL technique yields the causal and effect factors summarized in Table 3 as follows,

\section{Table 3}

Causal and effect factors

\begin{tabular}{llllllll}
\hline Cause (D-R) & $\mathrm{X}_{1}$ & $\mathrm{X}_{7}$ & $\mathrm{X}_{11}$ & $\mathrm{X}_{14}$ & $\mathrm{X}_{13}$ & $\mathrm{X}_{2}$ & $\mathrm{X}_{8}$ \\
Effect (D+R) & $\mathrm{X}_{12}$ & $\mathrm{X}_{4}$ & $\mathrm{X}_{5}$ & $\mathrm{X}_{3}$ & $\mathrm{X}_{10}$ & $\mathrm{X}_{9}$ & $\mathrm{X}_{6}$ \\
\hline
\end{tabular}

As we can observe from the results of Table 3, speeding up the activities is the number one factor in cause group followed by achieving new ideas, saving management time, better chance of achieving better technology, having better access to financial resources due to release on the existing equities, cost reduction and concentrating on more core activities.

On the effect side, employee reduction is the most important factor and it is on our top priority factor list. Access to new ideas, increasing the sense of competition, the ability to increase the quality of services, converting fixed cost items into variable ones for performance measurement and reducing the risk components are on the lower priorities.

\section{Conclusion}

In this survey, we have implemented DEMETL technique to find the causal and effect factors influencing outsourcing activities associated with water and switch management organization in one of populated cities in province of Semnan, Iran. The proposed model of this paper designed and distributed a questionnaire among 92 employees out of 120 people who worked for this organization and analyzed the results using DEMATEL method. The proposed model divided 14 factors into two groups of cause and effect factors. In the cause group, speeding up the activities is number one factor in cause group followed by achieving new ideas, saving management time, better chance of achieving better technology, having better access to financial resources due to release on the existing equities, cost reduction and concentrating on more core activities. On the effect side, employee reduction is the most important factor and it is on our top priority factor list. Access to new ideas, increasing the sense of competition, the ability to increase the quality of services, converting fixed cost items into variable ones for performance measurement and reducing the risk components are on the lower priorities.

\section{Acknowledgment}

The authors would like to thank the anonymous referees for their comments on earlier version of this paper.

\section{References}

Agrawal , M., Kishore, R., \& Rao, H.R. (2006). Market reactions to E-business outsourcing announcements: An event study. Information \& Management, 43, 861-873.

Amiri, M., Salehi Sadaghiyani, J., Payani, N., \& Shafieezadeh, M. (2011). Developing a DEMATEL method to prioritize distribution centers in supply chain. Management Science Letters, 1(3), 279288.

Belcourt, M. (2006). Outsourcing - The benefits and the risks. Human Resource Management Review, 16, 269-279.

Bardhan, A. D. \& Kroll, C. (2008). The New Wave of Outsourcing. University of California. Berkeley.

Bottani, E., \& Rizzi, A. (2006). A fuzzy TOPSIS methodology to support outsourcing of logistics services. Supply Chain Management: An International Journal, 11(4), 294-308. 
Chen, S. J., \& Hwang, C. L. (1992). Fuzzy multiple attribute decision making: Methods and applications. Berlin: Springer-Verlag.

Espino-Rodriguez, T. F., \& Padron-Robaina, V. (2004). Outsourcing and its impact on operational objectives and performance. Hospitality Management, 23, 287-306

Fontela, E., \& Gabus, A. (1976). The DEMATEL observer, DEMATEL 1976 Report. Switzerland Geneva: Battelle Geneva Research Center.

Hsu, P. F., \& Hsu, M. G. (2008). Optimizing the information outsourcing practices of primary care medical organizations using entropy and TOPSIS. Quality \& Quantity, 42, 181-201.

Jassbi, J., Mohamadnejad, F., Nasrollahzadeh, H. (2011). A Fuzzy DEMATEL Framework for modeling cause and effect relationships of strategy map. Expert systems with Applications, 38, 5967-5973.

Kahraman, C., Engin, O., Kabak, O., \& Kaya, I. (2009). Information systems outsourcing decisions using a group decision-making approach. Engineering Applications of Artificial Intelligence, 22, 832-841.

Klaas, S.B., McGlendon, J.A., \& Gainey, T.W. (2001). Outsourcing HR: The impact of organizational characteristics. Human Resource Management, 40(2), 125-138.

Lau, R.S., \& Hurly, C.N. (1997). Outsourcing through strategic alliances. Management Journal, 38(2), 52-57.

Lin, Y.T., Yang, Y.H., Kang, J.S., \& Yu, H.C. (2011).Using DEMATEL method to explore the core competences and causal effect of the IC design service company: An empirical case study. Expert Systems with Applications, 38(5), 6262-6268.

Masaaki, K., Mol, M. J., \& Murray, J. Y. (2008). Outsourcing, performance, and the role of ecommerce: A dynamic perspective. Industrial Marketing Management, 37(1), 37-45.

Moon, Y. (2010). Efforts and efficiency in partial outsourcing and investment timing strategy under market uncertainty. Computers \& Industrial Engineering, 59: 24-33.

Opricovic, S., \& Tzeng, G. H. (2007). Extended VIKOR method in comparison with outranking methods. European Journal of Operational Research, 178, 514-529.

Trevithick, S., Flabouris, A., Tall, G., Webber, C. (2003). International EMS System: Newsouth Wales. Australia Resucitation, 59(2), 70-165.

Tseng, M. L. (2009). A causal and effect decision making model of service quality expectation using grey-fuzzy DEMATEL approach. Expert Systems with Applications, 36, 7738-7748.

Yoon, K. P., \& Hwang, C. L. (1995). Multiple attribute decision making. Thousand Oaks, CA: Sage Publication.

Zhou, Q., Huang, W., \& Zhang, Y. (2011). Identifying critical success factors in emergency management using a fuzzy DEMATEL method. Safety Science, 49, 243-252. 